\title{
Genotype/phenotype correlations in 538 congenital adrenal hyperplasia patients from Germany and Austria: discordances in milder genotypes and in screened versus prescreening patients
}

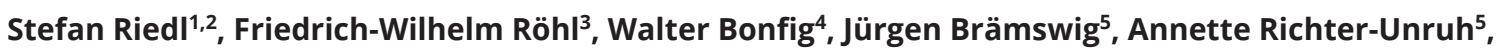
Susanne Fricke-Otto ${ }^{6}$, Markus Bettendorf 7 , Felix Riepe ${ }^{8}$, Gernot Kriegshäuser ${ }^{9}$, Eckhard Schönau ${ }^{10}$, Gertrud Even ${ }^{10}$, Berthold Hauffa ${ }^{11}$, Helmuth-Günther Dörr ${ }^{12}$, Reinhard W Holl ${ }^{13}$ and Klaus Mohnike ${ }^{14}$ on behalf of the AQUAPE CAH Study Group

${ }^{1}$ Division of Pediatric Pulmology, Allergology and Endocrinology, Department of Pediatrics, Medical University of Vienna, Vienna, Austria ${ }^{2}$ Department of Pediatrics, St. Anna Kinderspital, Medical University of Vienna, Vienna, Austria

${ }^{3}$ Department of Biometrics, Otto von Guericke Universität Magdeburg, Magdeburg, Germany

${ }^{4}$ Department of Pediatrics, Klinikum Wels-Grieskirchen, Wels, Austria

${ }^{5}$ Department of Pediatrics, Pediatric Endocrinology, Westfälische Wilhelmsuniversität Münster, Münster, Germany

${ }^{6}$ Department of Pediatrics, Pediatric Endocrinology, Helios Klinikum Krefeld, Krefeld, Germany

${ }^{7}$ Division of Pediatric Endocrinology and Diabetes, Department of Pediatrics, Ruprecht-Karls-Universität Heidelberg, Heidelberg, Germany

${ }^{8}$ Pediatric Endocrinology, Kronshagen, Kiel, Germany

${ }^{9}$ Institute of Clinical Chemistry and Laboratory Medicine, General Hospital Steyr, Steyr, Austria

${ }^{10}$ Department of Pediatrics, Pediatric Endocrinology, Universität zu Köln, Cologne, Germany

${ }^{11}$ Department of Pediatric Endocrinology, University of Duisburg-Essen, Essen, Germany

${ }^{12}$ Department of Pediatrics, Pediatric Endocrinology, Friedrich Alexander Universität Erlangen, Erlangen, Germany

${ }^{13}$ Institute of Epidemiology and Medical Biometry (ZIBMT), University of Ulm, Ulm, Germany

${ }^{14}$ Department of Pediatrics, Pediatric Endocrinology, Otto von Guericke Universität Magdeburg, Magdeburg, Germany

Correspondence should be addressed to S Riedl: Stefan.riedl@meduniwien.ac.at

\section{Abstract}

Congenital adrenal hyperplasia (CAH) due to CYP21A2 gene mutations is associated with a variety of clinical phenotypes (salt wasting, SW; simple virilizing, SV; nonclassical, NC) depending on residual 21 -hydroxylase activity. Phenotypes and genotypes correlate well in $80-90 \%$ of cases. We set out to test the predictive value of CAH phenotype assignment based on genotype classification in a large multicenter cohort. A retrospective evaluation of genetic data from 538 CAH patients (195 screened) collected from 28 tertiary centers as part of a German quality control program was performed. Genotypes were classified according to residual 21-hydroxylase activity (null, A,

\author{
Key Words \\ - 21-hydroxylase \\ - CYP21A2 \\ - genotype-phenotype \\ - congenital adrenal \\ hyperplasia \\ - $\mathrm{CAH}$
}

$B, C)$ and assigned clinical phenotypes correlated with predicted phenotypes, including analysis of Prader stages. Ultimately, concordance of genotypes with clinical phenotypes was compared in patients diagnosed before or after the introduction of nationwide CAH-newborn screening. Severe genotypes (null and A) correlated well with the expected phenotype (SW in 97 and 91\%, respectively), whereas less severe genotypes (B and C) correlated poorly (SV in $45 \%$ and NC in $57 \%$, respectively). This was underlined by a high degree of virilization in girls with $C$ genotypes (Prader stage $>1$ in $28 \%$ ). SW was diagnosed in $90 \%$ of screening-positive babies with classical CAH compared with $74 \%$ of prescreening patients. In our CAH series, assigned phenotypes were more severe than expected in milder genotypes and in screened vs prescreening patients. Diagnostic discrimination between phenotypes based on genotypes may prove overcome due to the overlap in their clinical presentations. 


\section{Introduction}

Congenital adrenal hyperplasia (CAH; incidence 1 in 10-15,000) due to 21-hydroxylase deficiency (21-OH) (CYP21A2; OMIM 201910) is an autosomal recessive disorder resulting in a deficient production of the steroid hormones cortisol and aldosterone. Consequently, the precursors of these hormones accumulate and are shunted in the androgen pathway causing androgen excess. A complete loss of 21-OH function results in salt-wasting (SW) phenotypes, while a minimal residual 21-OH production, which may be sufficient for aldosterone homeostasis, leads to simple virilizing (SV) or, less symptomatic, nonclassical CAH phenotypes (NC $\mathrm{CAH})$. However, subclinical or clinical mineralocorticoid deficiency, particularly in small infants, leads to an overlap in clinical presentation and assignment among SW and SV forms (1). In a compound heterozygous state with two different mutations, phenotype is generally deemed to be determined by the less severely affected allele. Classic CAH is clinically often characterized by ambiguous genitalia in $46, \mathrm{XX}$ individuals, whereas boys may show no signs at birth. Salt loss caused by aldosterone deficiency constitutes a life-threatening condition, particularly in early infancy when sodium intake is low and processing restricted due to physiological mineralocorticoid resistance (2). Without cortisone replacement, both sexes progress into precocious pseudopuberty. NC CAH has about 10-fold higher frequency than classic $\mathrm{CAH}$, usually manifesting during childhood with early pubarche and signs of androgen excess, but often goes unnoticed, particularly in boys. This explains the relatively low numbers of diagnosed boys and the unequal sex distribution in various studies $(3,4,5,6,7)$.

CYP21A2 lies on chromosome $6 \mathrm{p}$ in close proximity to its pseudogene (CYP21A2P), which is $96-98 \%$ homologous. Up to $75 \%$ of CAH mutations arise from the pseudogene by meiotic non-disjunction. Deletions (del) and CYP21A2/ CYP21A2P chimeric genes account for the remainder mutations. Most mutations are inherited and only a small proportion are due to rare or de novo mutations (8).

Correlation between the genotype and clinical phenotype depends on the degree of residual 21-hydroxylase activity. Many studies have sought to establish genotype-phenotype associations, investigating large nation- or population-based patient cohorts all over the world $(3,4,5,6,7,9,10,11,12)$. In general, severe mutations (residual 21-OH function $0-1 \%$ ) have been found to correlate well with the clinical phenotype (SW) whereas milder mutations show a greater variability with regard to individual clinical presentation of identical mutations.

Whereas in the past girls with classic $\mathrm{CAH}$ were generally detected at birth due to ambiguous genitalia, some affected boys were overlooked leading to unexplained death due to presumptive SW crises in several cases (13). For this reason, nationwide 17-hydroxyprogesterone (17-OHP) newborn screening was introduced in many countries throughout the world, including Germany (1999) and Austria (2001).

We report on allelic frequencies and genotypephenotype correlations in a pediatric cohort of $538 \mathrm{CAH}$ patients, the largest European cohort investigated to date. Furthermore, we analyzed the degree of virilization in affected girls with respect to genotype. Interestingly, we found considerable differences in genotype-phenotype correlations between prescreening and screened patients. To our knowledge, this is the first report of such data on screened CAH patients.

\section{Subjects and methods}

\section{AQUAPE database}

The AQUAPE (Working Group on Quality Assurance in Pediatric Endocrinology) CAH is an initiative prospectively recording clinical follow-up data from patients with $\mathrm{CAH}$ in a standardized database. This dataset is used for quality assurance and research. Altogether, 44 pediatric endocrine centers in Germany and Austria are participating in the initiative. Core data on phenotype, genetics and family history, as well as data on anthropometry, surgery, medication and biochemistry, collected during routine care at each clinical visit, are documented electronically at the individual center (http://buster.zibmt.uni-ulm.de). Twice a year, updated records are transferred in a pseudonymized form to the central data bank based in Ulm, Germany. Before processing for analysis, the data are verified and sent back to the original center for review if necessary. So far, data from 1298 patients, born between 1957 and 2013, comprising 22.552 outpatient appointments, have been recorded. Starting from Magedeburg, the AQUAPE $\mathrm{CAH}$ database was first approved by the data protection commissioner of the state of Saxony-Anhalt. Based on this central approval, each participating center attained institutional approval, complying with local ethical and data management guidelines. Consent has been obtained from each patient or subject after full explanation of the purpose and nature of all procedures used. 


\section{Clinical classification/phenotyping}

In the prescreening era, SW was diagnosed if a patient presented with dehydration, hyponatremia and hyperkalemia during the first 8 weeks of life, genitalia were ambiguous in females, and basal 17-OHP and renin activity and/or concentration were markedly elevated. Treatment consisted of hydrocortisone, fludrocortisone and salt replacement. After the introduction of the nationwide screening program (from 1 January 1999 in Germany and from 1 April 2001 in Austria) measuring 17-OHP levels on filter paper by a fluoroimmunometric assay (DELFIA, Wallac Oy, Turku, Finland), virtually all SW patients and most SV patients were recognized by their elevated 17-OHP concentrations. SV was defined by the absence of SW, genital ambiguity in girls, pseudoprecocious development, growth and bone age acceleration and high 17-OHP levels at repeat sampling or after Synacthen stimulation. Treatment was confined to hydrocortisone replacement. NC CAH was diagnosed in girls when they had no or minimal genital virilization, precocious pubarche, hirsutism or other clinical signs of hyperandrogenemia, and high 17-OHP levels after Synacthen stimulation $(>30 \mathrm{mmol} / \mathrm{L})$, according to the nomogram by New (14). Similarly, NC CAH was diagnosed in boys if precocious pubarche/virilization developed beyond 4 years of age accompanied by high17-OHP levels after Synacthen stimulation (1). Virilization in girls was graded according to Prader genital stages (PGS) with stages ranging from 1 (clitoromegaly) to 5 (complete virilization). In all patients, diagnosis of $\mathrm{CAH}$ was established or verified by a Pediatric Endocrinologist.

\section{CYP21A2 analysis/genotyping}

Different approaches and methods were used for genotype analysis. In general, Southern blot or, more recently, multiplex ligation-dependent probe amplification analysis (15) was used to detect gene deletions, chimeric genes and other gene alterations. Point mutations and small deletions as well as insertions were analyzed by Sanger sequencing, including the promotor region, from PCRamplified genomic DNA. Sequencing was the primary approach in $83.2 \%$ of the samples analyzed. A few centers first screened for the ten most common mutations (P30L, I2G, G110_8bp, I172N, E6 cluster, V281L, F306+t, Q318X, R356W, P453S) employing allele-specific PCR (16) and performed Sanger sequencing only if these results were inconclusive. Overall, this led to a sequencing rate close to $90 \%$. If available, parents and other family members were tested to confirm homozygosity/compound heterozygosity of affected individuals, delineate the mode of transmission if a child had more than two mutations and screen for carrier status in clinically unaffected relatives.

\section{Genotype classification}

Classification (null, A, B, C, D) was based on the scheme provided by Speiser (16). According to this grouping, the severity of mutations is classified by its residual enzymatic activity: 'null' (0\% residual function; del/con, G110_8bp, E6 cluster, F306+t, Q318X, R356W). 'A' (0-1\% residual function; $\mathrm{I} 2 \mathrm{G})$, 'B' (1-2\% residual function; $\mathrm{I} 172 \mathrm{~N})$ or 'C' (20-60\% residual function; P30L, V281L, P453S). Since $\mathrm{CAH}$ is an autosomal recessive disorder caused by homozygous or compound heterozygous mutations, the allele encoding for a protein with higher residual 21-OH activity is generally deemed to determine the severity of the overall genotype: 'null' if both alleles carried a 'null' mutation (null/null); ' $\mathrm{A}$ ' if $\mathrm{A} /$ null or $\mathrm{A} / \mathrm{A}$; ' $\mathrm{B}$ ' if $\mathrm{B} /$ null or $\mathrm{B} / \mathrm{A}$ or $\mathrm{B} / \mathrm{B}$; or ' $\mathrm{C}$ ' if $\mathrm{C} /$ null or $\mathrm{C} / \mathrm{A}$ or $\mathrm{C} / \mathrm{B}$ or $\mathrm{C} / \mathrm{C}$ alleles were present. Novel mutations on at least one allele with lacking information on impairment of 21-OH function were genotyped as ' $\mathrm{D}$ ' and excluded from analysis.

\section{Results}

\section{Eligible patients}

Information on genotype was complete for 660 (385 female/275 male; 58\%/42\%) among the 1298 patients recorded in the AQUAPE database. After exclusion of patients with incomplete phenotypes and group ' $\mathrm{D}$ ' genotypes, 195 and 343 patients with complete datasets remained in the screened and prescreening groups, respectively (Fig. 1).

Screened patients (median age 9 years (0.5-14)) had the expected equal sex distribution in line with autosomal recessive inheritance ( $48 \%$ girls). However, the prescreening group (median age 23 years (12-56)) had a significantly higher proportion of females (64\%). This was mainly due to the larger proportion of females with clinical diagnosis of NC CAH later in childhood.

\section{Allelic frequencies of CYP21A2 mutations}

Altogether, genetic data of 1320 alleles (Table 1) were available. The ten most common genetic variants were present in $96.8 \%$ of alleles, whereas rare or unknown

This work is licensed under a Creative Commons Attribution-NonCommercial-NoDerivatives 4.0 Internationab ticense.ifica com at $04 / 26 / 2023$ 10:04:41AM 


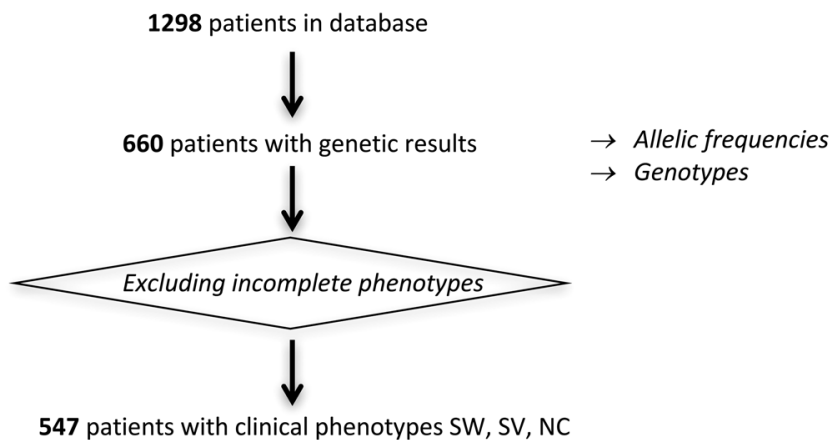

547 patients with clinical phenotypes SW, SV, NC

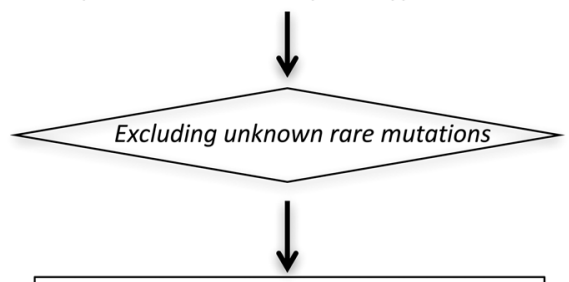

538 patients with genotypes null, A, B, C and complete clinical phenotypes SW, SV, NC

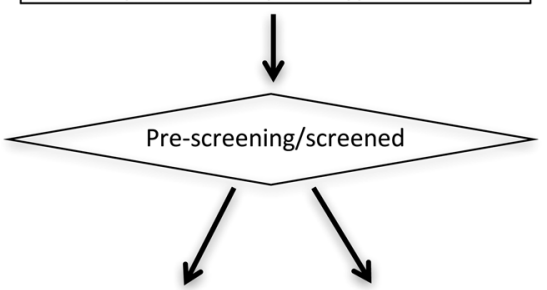

343 patients pre-screening

195 patients with screening

\begin{tabular}{|l|l|l|l|l|l|}
\hline SW 220 & SV 77 & NC 46 & SW 161 & SV 21 & NC 13 \\
\hline
\end{tabular}

$\rightarrow$ Genotype/phenotype correlations

$\rightarrow$ Subanalysis genotype/phenotype in pre-screening vs screened patients mutations were detected in 3.2\%. Del/conversions resulting in chimeric genes (29.6\%) and I2G (29.2\%) were most frequent, followed by I172N (13.1\%). Mutations with in vitro 21-OH activities between 10 and 60\% (P30L, V281L, P453S and some rare mutations) constituted $12.2 \%$ of the alleles. Two non-adjacent mutations on one allele were present in 34 alleles (2.6\%) and their genotypes classified according to the more severe mutation. Three or more adjacent mutations, comprising at least one severe mutation each, were classified as chimeric genes leading to a complete loss of 21-OH function. Among del/chimeric genes, 73\% were caused by deletions, whereas chimeric genes accounted for the remainder. In general, frequencies were similar to published data with some differences, in particular affecting $1172 \mathrm{~N}$ and V281L.

\section{Genotypes}

Homozygous genotypes were present in $37 \%$ of the patients with more than two-thirds either del/del or I2G/I2G, whereas $63 \%$ of patients were compound heterozygous. The distribution of genotypes was equal (c) 2019 The authors Published by Bioscientifica Ltd across sexes except for the null mutations that were found more frequently in males (30\% vs 19\% in females) and mutations, usually associated with a NC phenotype (P30L, V281L, P453S), that were more prevalent in females (25 vs 11\% in males). The latter is likely caused by an ascertainment bias and corresponds to the significantly higher proportion of females with $\mathrm{NC} \mathrm{CAH} \mathrm{in} \mathrm{our} \mathrm{cohort}$ (87 females vs 13\% males).

\section{Genotype-phenotype correlations}

In general, the frequency of the expected SW phenotype (Table 2) in patients with genotype null (97\%) and A (91\%) was similar to previously published studies. In contrast, the genotype-phenotype correlation was significantly lower for genotype B (46\%) and C (58\%) as compared to other studies. More than half of the patients $(54 \%)$ with genotype B (I172N) were classified as SW. Among genotype $\mathrm{C}$ patients, 78\% with a P30L mutation had classic CAH compared with 30\% with V281L. Accordingly, genotype C with P30L constituted one-third (32.6\%) of all patients with SV CAH. If virilization occurred in genotype C, PGS ranged from 1 to 5 in P30L, whereas V281L was 
Table 1 Frequencies (\%) of CYP21A2 variants compared with published data.

\begin{tabular}{l}
\hline Country \\
\hline$n$ (alleles) \\
Del/Kon \\
P30L \\
I2G \\
G110_8bp \\
I172N \\
E6 cluster \\
V281L \\
F306+t \\
Q318X \\
R356W \\
P453S \\
Other
\end{tabular}

\begin{tabular}{c}
\hline Germany + Austria present study \\
\hline 1.320 \\
29.6 \\
2.6 \\
29.2 \\
2.5 \\
13.1 \\
1.5 \\
7.8 \\
0.3 \\
4.6 \\
4.1 \\
1.4 \\
3.2
\end{tabular}

\begin{tabular}{c}
\hline USA (11) \\
\hline 3.005 \\
20.0 \\
2.6 \\
22.9 \\
2.1 \\
8.2 \\
2.1 \\
23.9 \\
- \\
3.5 \\
3.6 \\
- \\
- \\
\hline
\end{tabular}

\begin{tabular}{c}
\hline Argentina (7) \\
\hline 866 \\
11.2 \\
0.7 \\
20.6 \\
0.8 \\
8.2 \\
2.0 \\
26.2 \\
- \\
6.7 \\
4.2 \\
- \\
- \\
\hline
\end{tabular}

\begin{tabular}{c}
\hline Netherlands (5) \\
\hline 370 \\
31.9 \\
0.3 \\
28.1 \\
4.3 \\
12.4 \\
3.0 \\
2.2 \\
0.3 \\
3.5 \\
8.4 \\
0.5 \\
2.6
\end{tabular}

\begin{tabular}{cccc}
\cline { 1 - 1 } \cline { 1 - 1 } Germany $(4)$ & & Sweden $(9)$ \\
\cline { 1 - 1 } 310 & & 400 \\
27.4 & & 32.2 \\
2.6 & & 1.6 \\
30.3 & & 26.6 \\
1.6 & & 1.1 \\
19.7 & & 19.8 \\
1.0 & & 1.1 \\
2.9 & & 5.7 \\
0.3 & & $<1.0$ \\
4.8 & & 2.4 \\
4.5 & & 3.0 \\
0.3 & & $<1.0$ \\
4.6 & & $<5.0$ \\
\end{tabular}

associated with PGS 1 and 2 at the most. After excluding NC phenotypes, the second allele was affected by a more severe mutation (null, A, B) in all patients except for one SW (P30L/V281L) and $5 \mathrm{SV}$ patients with two C alleles (V281L/V281L, $n=3 ; \mathrm{V} 281 \mathrm{~L} / \mathrm{P} 453 \mathrm{~S}, n=1 ; \mathrm{P} 453 \mathrm{~S} / \mathrm{P} 453 \mathrm{~S}$, $n=1$ ) (Table 3). None of the patients with genotypes null, $\mathrm{A}$ and $\mathrm{B}$ had NC CAH. Analysis of relative frequencies of predicted phenotypes in relation to allelic combination of genotypes revealed that a more severe mutation on the second allele was associated with a more severe phenotype as compared to mutations displaying some residual function (Table 4).

\section{PGS in correlation with genotypes and phenotypes in $46, X X$ CAH patients}

PGS information was available in $84 \%$ of $46, \mathrm{XX}$ CAH (96\% of screened and $79 \%$ of prescreening patients) showing virilization (PGS 1-5) in 95\% and no virilization in $5 \%$. Severe virilization (PGS 4-5) was common in the null (56\%) and A (51\%) groups, compared with $24 \%$ in genotype $\mathrm{B}$ and $6 \%$ in genotype $\mathrm{C}$. At the extreme end, one $B$ and C patient each presented with PGS $5(2 / 10)$, whereas the remaining patients with PGS 5 had null (3/10) and A (5/10) genotypes. Twice as many patients with SW vs SV form (43 vs 22\%) had PGS 4, whereas PGS 3 was similar in both groups (29 vs $31 \%$ ) and mild virilization (PGS 1 and 2) occurred in considerably fewer patients with SW vs SV forms (24 vs 40\%) (Table 5).

\section{Genotype-phenotype correlations in prescreening vs screening patients}

Both the prescreening and the screened group were analyzed separately. Genotype A (I2G) was 8\% more frequent in screened than in prescreening patients
(40.4\%). Conversely, genotype C was $8.4 \%$ more prevalent in prescreening patients. Notably, distribution of PGS 1-5 as well as median PGS $(\sim 3)$ in female CAH patients was similar in both groups (Table 6).

a. Genotype-phenotype correlations in prescreening patients $(n=334)$

Regarding classic CAH, SW occurred in 74\%, correlating well with the literature. $4 \%$ of null and $15 \%$ of A had SV CAH. Accordance of B (SV) and C (NC) $(56 \%$ and $61 \%$, respectively), lay in a range found in some former studies $(4,5)$ and was pronouncedly higher than in screened patients (Table 2).

b. Genotype-phenotype correlations in screened patients $(n=204)$

SW was far above expected rates comprising $90 \%$ of patients with classic CAH. Null mutations (100\%) and A (99\%) showed a high degree of concordance with the SW phenotype, whereas correlation was very low in B (30\%) and C genotypes (52\%) (Table 2).

\section{Discussion}

Herein we present the largest European cohort of $\mathrm{CAH}$ patients reported to date including 538 patients with genotype-phenotype information. Allelic distribution of common mutations and the overall genotype distribution was largely similar to previously published cohorts $(4,5$, 9) except for $\mathrm{C}$ genotypes influenced by ethnic factors and NC CAH proportion in different studies. However, clinical classification according to genotype groups revealed weak correlation with the predicted phenotype in less severe genotypes (B and C) (Table 2). Discordance was even more pronounced in patients diagnosed after screening had been introduced, who were classified by clinicians as clinically more severe (SW in $90 \%$ compared with SW in $74 \%$ of

This work is licensed under a Creative Commons Attribution-NonCommercial-NoDerivatives 4.0 Internationab ticense.ifica com at $04 / 26 / 2023$ 10:04:41AM 
Table 2 Concordance of null, A, B, C genotypes with assigned phenotypes as compared to published data. Prescreening and screened groups are listed also separately.

\begin{tabular}{|c|c|c|c|c|c|c|c|}
\hline \multirow[b]{2}{*}{ Genotype/predicted phenotype } & \multicolumn{3}{|c|}{ Present study } & \multicolumn{4}{|c|}{ Former studies } \\
\hline & $\begin{array}{c}\text { All } \\
(n=538)\end{array}$ & $\begin{array}{l}\text { Prescreening } \\
\quad(n=334)\end{array}$ & $\begin{array}{l}\text { Screened } \\
(n=204)\end{array}$ & $\begin{array}{l}\text { USA (11) } \\
(n=1507)\end{array}$ & $\begin{array}{l}\text { Argentina } \\
(7)(n=454)\end{array}$ & $\begin{array}{c}\text { Netherland (5) } \\
(n=198)\end{array}$ & $\begin{array}{c}\text { Germany (4) } \\
\quad(n=155)\end{array}$ \\
\hline Null/SW\% & 97 & 96 & 100 & $\leq 100$ & 100 & 97 & 100 \\
\hline $\mathrm{A} / S W \%$ & 91 & 85 & 99 & 79 & 84 & 96 & 90 \\
\hline B/SV\% & 46 & 56 & 30 & 76 & 87 & 53 & 74 \\
\hline $\mathrm{C} / \mathrm{NC} \%$ & 58 & 61 & 52 & $>90$ & 100 & 100 & 65 \\
\hline
\end{tabular}

prescreening patients). This might in part be caused by the fact that genotype A was $8 \%$ more frequent in screened patients and genotype $\mathrm{C}$ overrepresented $(+8.4 \%)$ in the prescreening group. However, PGS in female patients were overall identical in screened and prescreening patients (Table 6). Hence, relatively more patients of the screened cohort were treated with mineralocorticoids.

Deletions/chimeric genes and I2G comprised almost $30 \%$ each, followed by I172N in $13.1 \%$ (Table 1 ). C genotype mutations were found in $11.8 \%$, led by V281L (65.6\% of C) and P30L (25\% of C). Some CYP21A2 mutations such as I2G and V281L have strong ethnic distributions due to founder effects. For instance, V281L was found to be more prevalent in patients of Mediterranean descent, explaining the higher numbers in studies of such patients $(7,11)$. However, detailed information on ethnic distribution was not available in our cohort.

Many studies have investigated genotype-phenotype relations in large national and multiethnic cohorts. In general, severe genotypes leading to SW uniformly showed a strong correlation with the clinical phenotypes. In our study, overall genotype-phenotype correlation was also high in severe mutations (null: 97\%; A: 91\%), but extraordinarily low in B (46\%) and C (58\%) phenotypes. In comparison (Table 2), former studies reported $97-100 \%$ concordance in null, $79-96 \%$ in $\mathrm{A}, 53-87 \%$ in B and $65-100 \%$ in C genotypes $(4,5,7,11)$. Regarding genotype C, $78 \%$ of our patients with a P30L mutation and $30 \%$ of V281L patients, respectively, had classical CAH (Table 3). PGS correlated with enzymatic loss in severe genotypes

Table 3 Genotype/phenotype correlations in C genotypes (P30L, V281L, P453S).

\begin{tabular}{|c|c|c|c|c|}
\hline $\boldsymbol{n}$ (\% of total) & sw & sv & NC & Total \\
\hline P30L & $7(26)^{a}$ & $14(52)$ & $6(22)$ & $27(100)$ \\
\hline V281L & $4(6)$ & $15(24)^{a}$ & $45(70)$ & $64(100)$ \\
\hline P453S & - & $1(20)$ & $4(80)$ & $5(100)$ \\
\hline
\end{tabular}

aOne patient each with P30L/V281L (SW) and V281L/P453S (SV) was assigned to the P30L and the V281L group, respectively, and counted only once.
(Table 5) but virilization was also common in genotype C, especially in female P30L patients. Variably, such results on metabolic and clinical phenotypes (PGS) in C genotypes have been observed before: Classical CAH was found in $11 \%$ (4) and 30\% (17) of V281L patients and in two-thirds of patients with P30L mutations $(4,7,17)$ associated with virilization in $24 \%$ of V281L and in $66 \%$ of P30L patients in the latter study (17).

The reasons for these observed discrepancies have not been clarified yet. Some residual activity, for example in I2G (splice site mutation) resulting in SV CAH may occur (up to $20 \%$ in 11) even though it is classified as a severe mutation usually leading to SW (18). Furthermore, effects from additional pathways that regulate the severity of enzymatic loss such as the androgen backdoor pathway (19) may play a critical role in individual patients causing more heterogeneous phenotypes. In addition, we observed increased clinical severity in compound heterozygous, who carried a more severe mutation on the other allele (Table 4). This would be supported by the observation of higher biochemical androgen response to ACTH stimulation in compound heterozygous NC CAH with one classical haplotype vs homozygotes with two mild mutations, although clinical effects have not been observed previously (20). From a functional perspective, ambiguity is reflected by variable degrees of residual in vitro activity reported in different studies, ranging between $<2-5 \%$ in $\operatorname{I} 172 \mathrm{~N}(21,22)$ and $10-60 \%$ in P30L $(23,24)$. Finally, particularly in patients with P30L mutations, additional mutations in the promotor or P30L mutations as part of minor gene conversions/chimeric genes may go unnoticed $(25,26)$. All these factors may contribute to the experience, that - apart from the null genotype, resulting in a complete loss of $21-\mathrm{OH}$ function - clinical presentation of $\mathrm{CAH}$ shows a free flow depending on residual 21-OH function and impact of additional cofactors that are largely unknown.

Notably, assigned phenotypes were more severe in screened $(90 \% \mathrm{SW})$ vs prescreening patients $(74 \% \mathrm{SW})$ despite similar clinical characteristics (PGS; Table 6). In

This work is licensed under a Creative Commons Attribution-NonCommercial-NoDerivatives 4.0 Internationab sicense.ifica . com at 04/26/2023 10:04:41AM 
Table 4 Relative frequencies of predicted phenotypes in relation to allelic combination of genotypes.

\begin{tabular}{|c|c|c|c|}
\hline \multicolumn{2}{|c|}{ Genotype } & \multirow[b]{2}{*}{$n$} & \multirow[b]{2}{*}{ Predicted phenotype } \\
\hline Allele 1 & Allele 2 & & \\
\hline Null & Null & 150 & SW \\
\hline A & Null & 123 & SW \\
\hline$A$ & A & 62 & SW \\
\hline B & Null & 57 & SV \\
\hline B & $A$ or $B$ & 45 & SV \\
\hline C & Null & 42 & NC \\
\hline C & $A$ or $B$ & 39 & NC \\
\hline C & C & 20 & NC \\
\hline
\end{tabular}

particular, genotype $\mathrm{B}$, suggesting SV CAH, was present in 70 vs $44 \%$ of screened vs prescreening SW CAH patients, respectively (Table 2). Since absolute 17-OHP levels at newborn screening may not discriminate between SW and SV forms and confounding factors such as prenatal glucocorticoid treatment or postnatal stress interfere, $\mathrm{CAH}$ consensus guidelines recommend treating newborns with classic CAH with glucocorticoids, fludrocortisone and salt supplements, starting from diagnosis by neonatal 17-OHP screening (27). Clinical or subclinical SW is considerably more frequent than SV and may not be obvious before the end of the first week of life or even until several weeks after birth. However, because of the non-SW CAH likelihood of around $25 \%$, the current guidelines recommend critically reevaluating the further need for mineralocorticoid treatment after early infancy assessing blood pressure, plasma renin activity, and the aldosterone-to-renin ratio and adjusting treatment accordingly (27). Therefore, the current approach to provide for potential SW in all patients with elevated 17-OHP at screening by adding a standard dose of fludrocortisone and salt supplements will maximize safety. On the other hand, fludrocortisone overtreatment - theoretically in one-fourth of patients who will rather have SV CAH - might lead to hypertension that could go unnoticed for months or even years with potential long-term effects in later life. Additionally, blood pressure measurements in infants/children in an ambulatory setting may be unreliable if the child is not calm and therefore easily relativized or disregarded if high. In a recent study from the same working group (AQUAPE database), elevated blood pressure was found in $12.5 \%$ of 3 - to 18 -year-old CAH patients $(n=716)$, with an even higher proportion in the younger age group (18.5 vs $4.9 \%$ in adolescents) (28). Generally, elevated blood pressure together with suppressed renin levels should always prompt the physician to reduce or stop fludrocortisone treatment. However, even if this decision is theoretically evident, it may be precarious to make in an individual clinical setting, particularly in very young children. Neonatal management and clinical guidance may be optimized by second-tier tests which are nowadays available in many institutions, such as tandem mass spectrometry or rapid genetic tests, for example screening for the most common mutations and deletions (29).

Our study has several strengths. We have investigated the so far largest European cohort of CAH patients arising from 28 centers. Furthermore, the quality of genetic data was superior, with a sequencing rate close to $90 \%$, far exceeding other large-scale studies (11). In addition, this is the first report of genotype-phenotype correlations in a large young patient cohort diagnosed after the introduction of screening as compared to the prescreening era. As to limitations, despite clear diagnostic criteria and thorough data editing we cannot exclude arbitrary overestimation of severity of clinical phenotypes. If in doubt from a clinical perspective, the presence of mineralocorticoid treatment might have influenced classification of an individual patient as SW, causing a bias toward higher numbers of

Table 5 Prader genital stages (\%) stratified according to genotypes (null, A, B, C, D) and according to clinical phenotypes (SW, SV, NC).

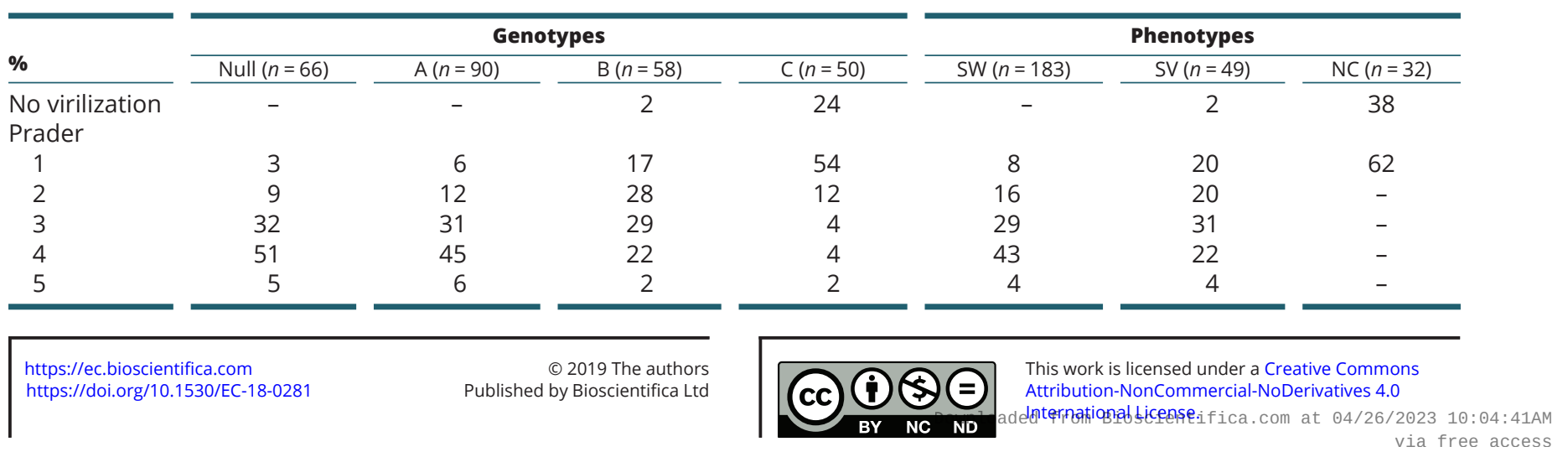


Table 6 Prader stages (\%) in prescreening and screened $46, \mathrm{XX}$ individuals with $\mathrm{CAH}$.

\begin{tabular}{lccc}
\hline Prader stage & Prescreening $\%(n=174)$ & & Screened \% $(n=90)$ \\
\cline { 1 - 1 } No virilization & 3 & 9 \\
1 & 15 & 19 \\
2 & 17 & 12 \\
3 & 26 & 26 \\
4 & 36 & 30 \\
5 & 3 & 4 \\
Prader stage (1-5) & 3 & 3 \\
median & & \\
\hline
\end{tabular}

severe phenotypes, particularly in patients diagnosed after screening had been introduced. Not least, shortcomings of molecular genetic techniques, in particular if sequencing was not carried out $(\sim 10 \%$ in our series), might have resulted in additional allelic mutations being overlooked.

In conclusion, in this the largest European study reported to date, CYP21A2 phenotype prediction was reasonably conclusive in severe genotypes but unreliable in weaker genotypes. Current management guidelines recommending to treat all screening-positive babies as SW CAH might result in overrating of the clinical phenotype and mineralocorticoid overtreatment in a small but significant proportion of patients. Since CAH has to be regarded as a continuum with fluent boundaries between SW and SV phenotypes, subclassification should be rather driven by clinical and biochemical markers than by genotype.

\section{Declaration of interest}

The authors declare that there is no conflict of interest that could be perceived as prejudicing the impartiality of the research reported.

\section{Funding}

This research did not receive any specific grant from any funding agency in the public, commercial or not-for-profit sector

\section{Author contribution statement}

F-W Röhl, K Mohnike, R W Holl carried out study design and project management. Data collection was done by S Riedl, W Bonfig, J Brämswig, A Richter-Unruh, S Fricke-Otto, M Bettendorf, F Riepe, E Schönau, G Even, B Hauffa and H-G Dörr. Data analysis was done by F-W Röhl, K Mohnike, $S$ Riedl and G Kriegshäuser. Preparation of the manuscript was done by $S$ Riedl. Editing and final approval of the manuscript were done by all authors.

\section{References}

1 White PC \& Speiser PW. Congenital adrenal hyperplasia due to 21-hydroxylase deficiency. Endocrine Reviews 200021 245-291. (https://doi.org/10.1210/edrv.21.3.0398)
2 Bauer JH. Age-related changes in the renin-aldosterone system. Physiological effects and clinical implications. Drugs and Aging 1993 3 238-245. (https://doi.org/10.2165/00002512-199303030-00005)

3 Jääskeläinen J, Levo A, Voutilainen R \& Partanen J. Population-wide evaluation of disease manifestation in relation to molecular genotype in steroid 21-hydroxylase (CYP21) deficiency: good correlation in a well defined population. Journal of Clinical Endocrinology and Metabolism 199782 3293-3297. (https://doi.org/10.1210/ jcem.82.10.4271)

4 Krone N, Braun A, Roscher AA, Knorr D \& Schwarz HP. Predicting phenotype in steroid 21-hydroxylase deficiency? Comprehensive genotyping in 155 unrelated, well defined patients from southern Germany. Journal of Clinical Endocrinology and Metabolism 200085 1059-1065. (https://doi.org/10.1210/jcem.85.3.6441)

5 Stikkelbroeck NM, Hoefsloot LH, de Wijs IJ, Otten BJ, Hermus AR \& Sistermans EA. CYP21 gene mutation analysis in 198 patients with 21-hydroxylase deficiency in the Netherlands: six novel mutations and a specific cluster of four mutations. Journal of Clinical Endocrinology and Metabolism 200388 3852-3859. (https://doi. org/10.1210/jc.2002-021681)

6 Finkielstain GP, Chen W, Mehta SP, Fujimura FK, Hanna RM, Van Ryzin C, McDonnell NB \& Merke DP. Comprehensive genetic analysis of 182 unrelated families with congenital adrenal hyperplasia due to 21-hydroxylase deficiency. Journal of Clinical Endocrinology and Metabolism 201196 E161-E172. (https://doi. org/10.1210/jc.2010-0319)

7 Marino R, Ramirez P, Galeano J, Perez Garrido N, Rocco C, Ciaccio M, Warman DM, Guercio G, Chaler E, Maceiras M, et al. Steroid 21-hydroxylase gene mutational spectrum in 454 Argentinean patients: genotype-phenotype correlation in a large cohort of patients with congenital adrenal hyperplasia. Clinical Endocrinology 201175 427-435. (https://doi.org/10.1111/j.13652265.2011.04123.x)

8 Parsa AA \& New MI. Steroid 21-hydroxylase deficiency in congenital adrenal hyperplasia. Journal of Steroid Biochemistry and Molecular Biology 2017165 2-11. (https://doi.org/10.1016/j. jsbmb.2016.06.015)

9 Wedell A. An update on the molecular genetics of congenital adrenal hyperplasia: diagnostic and therapeutic aspects. Journal of Pediatric Endocrinology and Metabolism 199811 581-589. (https://doi. org/10.1515/JPEM.1998.11.5.581)

10 Dracopoulou-Vabouli M, Maniati-Christidi M \& Dacou-Voutetakis C. The spectrum of molecular defects of the CYP21 gene in the Hellenic population: variable concordance between genotype and phenotype in the different forms of congenital adrenal hyperplasia. Journal of Clinical Endocrinology and Metabolism 200186 2845-2848. (https:// doi.org/10.1210/jcem.86.6.7574)

11 New MI, Abraham M, Gonzalez B, Dumic M, Razzaghy-Azar M, Chitayat D, Sun L, Zaidi M, Wilson RC \& Yuen T. Genotypephenotype correlation in 1,507 families with congenital adrenal hyperplasia owing to 21-hydroxylase deficiency. PNAS $2013 \mathbf{1 1 0}$ 2611-2616. (https://doi.org/10.1073/pnas.1300057110)

12 De Carvalho DF, Miranda MC, Gomes LG, Madureira G, Marcondes JA, Billerbeck AE, Rodrigues AS, Presti PF, Kuperman H, Damiani D, et al. Molecular CYP21A2 diagnosis in 480 Brazilian patients with congenital adrenal hyperplasia before newborn screening introduction. European Journal of Endocrinology 2016175 107-116. (https://doi.org/10.1530/EJE-16-0171)

13 Strnadová KA, Votava F, Lebl J, Mühl A, Item C, Bodamer OA, Torresani T, Bouska I, Waldhauser F \& Sperl W. Prevalence of congenital adrenal hyperplasia among sudden infant death in the Czech Republic and Austria. European Journal of Pediatrics 2007166 1-4. (https://doi.org/10.1007/s00431-006-0154-8)

14 New MI, Lorenzen F, Lerner AJ, Kohn B, Oberfield SE, Pollack MS, Dupont B, Stoner E, Levy DJ, Pang S, et al. Genotyping steroid 21-hydroxylase deficiency: hormonal reference data. Journal of 
Clinical Endocrinology and Metabolism 198357 320-326. (https://doi. org/10.1210/jcem-57-2-320)

15 Schouten JP, Mc Elgunn CJ, Waaijer R, Zwijnenburg D, Diepvens F $\&$ Pals G. Relative quantification of 40 nucleic acid sequences by multiplex ligation-dependent probe amplification. Nucleic Acids Research 200230 e57. (https://doi.org/10.1093/nar/gnf056)

16 Speiser PW, Dupont J, Zhu D, Serrat J, Buegeleisen M, Tusie-Luna MT, Lesser M, New MI \& White PC. Disease expression and molecular genotype in congenital adrenal hyperplasia due to 21-hydroxylase deficiency. Journal of Clinical Investigation 199290 584-595. (https:// doi.org/10.1172/JCI115897)

17 Gurgov S, Bernabé KJ, Stites J, Cunniff CM, Lin-Su K, Felsen D, New MI \& Poppas DP. Linking the degree of virilization in females with congenital adrenal hyperplasia to genotype. Annals of the New York Academy of Sciences 20171402 56-63. (https://doi.org/10.1111/ nyas.13370)

18 Schulze E, Scharer G, Rogatzki A, Priebe L, Lewicka S, Bettendorf M, Hoepffner W, Heinrich UE \& Schwabe U. Divergence between genotype and phenotype in relatives of patients with the intron 2 mutation of steroid-21hydroxylase. Endocrine Research 199521 359-364. (https://doi. org/10.3109/07435809509030452)

19 Kamrath C, Hartmann MF, Remer T \& Wudy SA. The activities of $5 \alpha$-reductase and 17,20-lyase determine the direction through androgen synthesis pathways in patients with 21-hydroxylase deficiency. Steroids 201277 1391-1397. (https://doi.org/10.1016/j. steroids.2012.08.001)

20 Speiser PW \& New MI. Genotype and hormonal phenotype in nonclassical 21-hydroxylase deficiency. Journal of Clinical Endocrinology and Metabolism 198764 86-91. (https://doi. org/10.1210/jcem-64-1-86)

21 Chiou SH, Hu MC \& Chung BC. A missense mutation at Ile172 $\rightarrow$ Asn or Arg356 $\rightarrow$ Trp causes steroid 21-hydroxylase deficiency. Journal of Biological Chemistry 1990265 3549-3552.

22 Tusie-Luna MT, Traktman P \& White PC. Determination of functional effects of mutations in the steroid 21-hydroxylase gene (CYP21) using recombinant vaccinia virus. Journal of Biological Chemistry 1990265 20916-20922.
23 Hu MC, Hsu LC, Hsu NC \& Chung BC. Function and membrane topology of wild-type and mutated cytochrome P-450c21. Biochemical Journal 1996316 325-329. (https://doi.org/10.1042/ bj3160325)

24 Tusie-Luna MT, Speiser PW, Dumic M, New MI \& White PC. A mutation (Prof-30 to Leu) in CYP21 represents a potential nonclassic steroid 21-hydroxylase deficiency allele. Molecular Endocrinology 1991 5 685-692. (https://doi.org/10.1210/mend-5-5-685)

25 Dolzan V, Stopar-Obreza M, Zerjav-Tansek M, Breskvar K, Krzisnik C \& Battelino T. Mutational spectrum of congenital adrenal hyperplasia in Slovenian patients: a novel Ala15Thr mutation and Pro30Leu within a larger gene conversion associated with a severe form of the disease. European Journal of Endocrinology 2003149 137-144. (https:// doi.org/10.1530/eje.0.1490137)

26 Baumgartner-Parzer SM, Schulze E, Waldhäusl W, Pauschenwein S, Rondot S, Nowotny P, Meyer K, Frisch H, Waldhauser F \& Vierhapper H. Mutational spectrum of the steroid 21-hydroxylase gene in Austria: identification of a novel missense mutation. Journal of Clinical Endocrinology and Metabolism 200186 4771-4775. (https:// doi.org/10.1210/jcem.86.10.7898)

27 Speiser PW, Arlt W, Auchus RJ, Baskin LS, Conway GS, Merke DP, Meyer-Bahlburg HFL, Miller WL, Murad MH, Oberfield SE, et al. Congenital adrenal hyperplasia due to steroid 21-hydroxylase deficiency: an Endocrine Society clinical practice guideline. Journal of Clinical Endocrinology and Metabolism 2018103 4043-4088. (https:// doi.org/10.1210/jc.2018-01865)

28 Bonfig W, Roehl FW, Riedl S, Dörr HG, Bettendorf M, Brämswig J, Schönau E, Riepe F, Hauffa B, Holl RW, et al. Blood pressure in a large cohort of children and adolescents With classic adrenal hyperplasia (CAH) due to 21-hydroxylase deficiency. American Journal of Hypertension 201629 266-272. (https://doi.org/10.1093/ ajh/hpv087)

29 Németh S, Riedl S, Kriegshäuser G, Baumgartner-Parzer S, Concolino P, Neocleous V, Phylactou LA, Borucka-Mankiewicz M, Onay $\mathrm{H}$, Tukun A, et al. Reverse-hybridization assay for rapid detection of common CYP21A2 mutations in dried blood spots from newborns with elevated 17-OH progesterone. Clinica Chimica Acta 2012414 211-214. (https://doi.org/10.1016/j.cca.2012.09.013)

Received in final form 4 December 2018

Accepted 8 January 2019

Accepted Preprint published online 8 January 2019 https://ec.bioscientifica.com https://doi.org/10.1530/EC-18-0281 (c) 2019 The authors Published by Bioscientifica Ltd
This work is licensed under a Creative Commons Attribution-NonCommercial-NoDerivatives 4.0 Internationab sicense.ifica . com at 04/26/2023 10:04:41AM 